\title{
Correction to: On the Move to Meaningful Internet Systems
}

Hervé Panetto, Christophe Debruyne (iD, Martin Hepp, Dave Lewis,

Claudio Agostino Ardagna, and Robert Meersman

\section{Correction to: \\ H. Panetto et al. (Eds.): On the Move to Meaningful Internet Systems, LNCS 11877, https://doi.org/10.1007/978-3-030-33246-4}

The affiliation of Martin Hepp was incorrect. The correct information is given below. Universität der Bundeswehr München, Munich, Germany

The chapter 'VoIDext: Vocabulary and Patterns for Enhancing Interoperable Datasets with Virtual Links' was originally published as non-open access and has now been converted to open access under a CC BY 4.0 license and the copyright holder updated to 'The Author(s)'.

The updated version of the book can be found at https://doi.org/10.1007/978-3-030-33246-4_38

https://doi.org/10.1007/978-3-030-33246-4

(C) Springer Nature Switzerland AG 2019

H. Panetto et al. (Eds.): OTM 2019, LNCS 11877, p. C1, 2019.

https://doi.org/10.1007/978-3-030-33246-4_47 